\title{
When familiarity breeds contempt, absence makes the heart grow fonder: Effects of exposure and delay on taste pleasantness ratings
}

\author{
DAVID J. STANG \\ Queens College, of the City University of New York, Flushing, New York 11367
}

\begin{abstract}
The effects of repeated exposure and delay on taste pleasantness ratings were explored in a study involving 10 female subjects. Subjects tasted and rated for pleasantness small quantities of 15 spices 10 times each in Session I and 1 week later (Session II) made four additional tastes and ratings of each of the spices. Pleasantness ratings were a decreasing concave upward function of trials during each session, the decay in pleasantness being more rapid in Session II than in Session I: Initial trials in both sessions did not differ in rated pleasantness. Results suggest that some satiation effects dissipate with time while others are cumulative.
\end{abstract}

Repeated exposure to novel visual and auditory stimuli alters the affective value of these stimuli, as many recent studies (reviewed in Stang, 1974) have shown. One yet unexplored question is whether repeated exposure through a modality other than vision or hearing has the same affective consequences as visual or auditory exposure. Such a finding would have implications for our understanding of the cognitive mechanisms involved in the process. Surprisingly little research has examined the effects of repeated tasting on changes in the affective value of the thing tasted, although a large, marginally relevant literature exists on conditioned taste aversions (e.g., Domjan, 1972; Elkins, 1973; Green \& Rachlin, 1973; Wilcoxon, Dragoin, \& Kral, 1971). One interesting but unnoticed finding of this literature is that a rat's preference for a saccharin solution is an increasing concave downward function of the extent of pre-exposure to such a solution. This finding may be inferred from data reported by Elkins (1973), although he does not discuss his results from this perspective. Other research (see Domjan, 1972) has shown that animals repeatedly allowed to ingest a flavored substance subsequently show weaker aversions to that substance following pairing with a noxious UCS. One explanation for this may be that repeatedly tasting a flavored substance makes the substance more pleasant. Among human subjects, Dickens (1946) and Zajonc (1968)

The author would like to thank Anthony DeStefano for conducting the experiment reported here and Daniel Berlyne, Margaret Matlin, and Hardy Wilcoxon for their helpful comments on a previous draft of this manuscript. Margaret Matlin also sponsors this paper and takes full editorial responsibility for its content. Requests for reprints should be sent to David Stang, Department of Psychology, Queens College of the City University of New York, Flushing, New York 11367. suggest that a person's consumption of food may determine his food preferences rather than (or at least in addition to) vice versa, although they only provide correlational support for this position.

Apart from examining affective consequences of repeated tastings, the experiment described below has a second purpose. It has been proposed (Stang, 1975) that once a stimulus becomes familiar, continued massed exposure to it causes an unpleasant state of satiation to develop, which depresses affective ratings: familiarity breeds contempt. Satiation effects are hypothesized to disappear over time (the "oldie but goodie" phenomenon in pop music), the absence of exposure making the heart grow fonder. The study reported below examines the permanence of satiation effects.

\section{METHOD}

\section{Subjects}

Subjects were 10 female undergraduate students enrolled in the author's social psychology course, who participated in the experiment for course credit.

\section{Procedure}

Subjects were tested individually in two sessions. Session I lasted approximately $60 \mathrm{~min}$, and Session II, 1 week later, lasted $15 \mathrm{~min}$. At the start of Session I, subjects were told "You'll be presented with different spices. Your task will be to rate each spice on the rating scale. Call the first number that seems appropriate to you. You may rinse your mouth with the water and either spit it into the pail or swallow it, whichever you prefer." Subjects were told that some spices might get more pleasant, others less pleasant, and others might not change in pleasantness with repeated tastings.

Subjects were given a seven-point pleasant-unpleasant rating scale, with the quantifiers extremely, moderately, and slightly. After each tasting, the subject was instructed to call out a scale value representing her feeling about the taste, and the experimenter recorded this, to reduce the effects of previous ratings. During the experimental session, the experimenter would place a small quantity of a given spice on the subject's tongue with a wooden coffee stirrer. The subject had 3 sec to call out a 


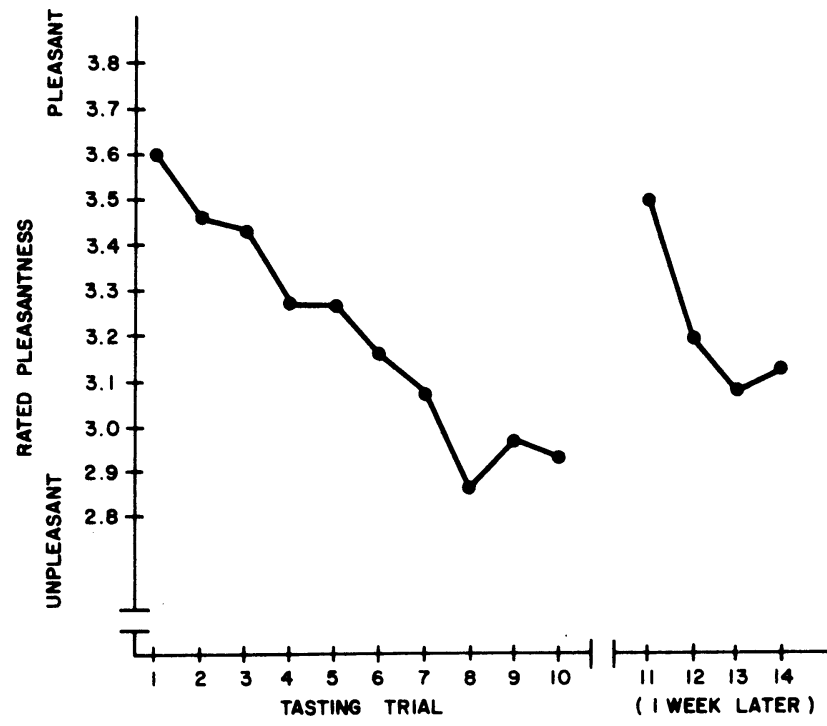

Figure 1. Rated pleasantness of 15 spices as a function of tasting trial.

rating and then $10 \mathrm{sec}$ to relax and rinse her mouth if she desired. Music was played during the experiment to reduce boredom effects on the taste ratings.

Subjects tasted 15 spices (chile powder, mustard, thyme, basil, cinnamon, cloves, nutmeg, allspice, paprika, garlic salt, butter salt, marjoram, parsley, curry, and ginger) in a constant order, which was repeated 10 times in Session I, 4 times in Session II, making a total of 210 pleasantness ratings. The exposure paradigm may be seen as a variant of that used by Berlyne (1970, Experiments I and II).

\section{RESULTS}

Data were analyzed by repeated measures analysis of variance in a subjects by trials design. Figure 1 indicates the overall pattern of pleasantness ratings as a function of trials.

Pleasantness ratings decreased over Trials 1-10 $\left[\mathrm{F}_{\text {trials }}(9,1260)=10.744, \mathrm{p}<.0001\right]$ and from Trials 11 through $14\left[\mathrm{~F}_{\text {trials }}(3,420)=7.210, \mathrm{p}=.0002\right]$. Rated pleasantness increased from Trials 10 to 11 , during the 1 -week delay $\left[F_{\text {trials }}(1,140)=29.435\right.$, $\mathrm{p}<.0001]$ and in fact, Trials 1 and 11 did not significantly differ $\left[F_{\text {trials }}(1,140)=.688, p>.5\right]$.

Although subjects did not significantly differ in their mean pleasantness ratings, significant Subject by Trials interactions occurred on Trials 1-10 [F subjects by trials $(81,1260)=2.436, p<.0001]$ and on Trials $10-11$ $\left[\mathrm{F}_{\text {subjects by trials }}(9,140)=5.508, \mathrm{p}<.0001\right]$ but not on Trials $11-14\left[\mathrm{~F}_{\text {subject }}\right.$ by trials $(27,420)=1.226$, $\mathrm{p}>.2]$.

These interactions resulted from fairly smooth decay functions for 7 of the 10 subjects, while the other 3 subjects showed fairly constant pleasantness ratings across the first 10 trials. On Trials 11-14, the group curve does describe the individual curves of these three subjects.

\section{DISCUSSION}

The findings of the present study indicate that rated pleasantness of tastes is affected by repeated exposure. Further, taste pleasantness ratings were in the same functional relationship to exposure frequency on Trials 1-10 that has been found with visual stimuli in a similar exposure paradigm (Berlyne, 1970). Recalling Elkins (1973) finding, noted above, that with a delay between exposure and preference choice, taste preference is an increasing concave downward function of exposure frequency, we might tentatively conclude that gustatory, visual, and auditory affective judgments all behave in the same way: Stang (1974) suggests that with repeated exposure and a rating delay, affective judgments may become more positive, while with no delay, they may become more negative. Further experimentation is required to establish this hypothesis.

The finding that affective ratings jumped during the 1-week delay to a level not significantly different from the original ratings (Trial 11 vs. Trial 1) suggests that absence does "make the heart grow fonder" but not fonder than it was at its previous affective peak. Whether this return always occurs is a question for future research, as is the specification of the conditions which determine the rate of this return.

Of particular interest is the apparently steeper decay in affect on Trials 11-14 than on Trials 1-4. Apparently, there is some long-lasting effect of stimulus satiation. This finding might have application in avoidance conditioning of a liked object or preferred behavior in the absence of a UCS. Rather than try to discourage the subject from engaging in a preferred but objectionable behavior, a therapist might require the subject to repeatedly engage in it, inducing satiation and subsequent avoidance. Such a "satiation therapy" has been successfully used to eliminate or reduce hoarding (Allyon, 1963) and cigarette smoking (e.g., Lichtenstein, Harris, Birchler, Wahl, \& Schmahl, 1973; Marrone, Merksamer, \& Salzberg, 1970). Such satiation procedures could be extended to extinguish undesirable verbal habits, certain repetition compulsions, preferences for certain tastes, etc. The latter is suggested in the results of Singer (1973), who found that hungry babies looked at food-related stimuli and that satiated babies looked away. While satiation to food is necessarily a short-lived phenomenon, satiation to specific foods might be much longer lasting.

Normally, people avoid satiation effects by avoiding continued exposure to the unpleasantly familiar and turn their attention toward the relative more novel. So we do not envy coffee tasters and others who must continue to judge the affective qualities of a product over thousands of tastings. For spices, at least, too great a familiarity may breed contempt.

\section{REFERENCES}

Allyon, T. Intensive treatment of psychotic behavior by satiation and food reinforcement. Behavior Research and Therapy, 1963, 1, 53-61.

BerYlNE, D. E. Novelty, complexity, and hedonic value. Perception \& Psychophysics, 1970, 8, 279-286.

DickENS, D. Menu planning and food habits. Journal of the American Dietetic Association, 1946, 22, 890-896.

Domsan, M. CS preexposure in taste-aversion learning: Effects of deprivation and preexposure duration. Learning and Motivation, 1972, 3, 389-402.

Elkins, R. L. Attenuation of drug-induced bait shyness to a palatable solution as an increasing function of its availability prior to conditioning. Journal of Behavioral Biology, 1973, 9, 221-226.

Elkins, R. L. Individual differences in bait shyness: Effects of drug dose and measurement technique. Psychological Record, 1973, 23, 349-358. 
GreEN, L., \& RAChLin, H. The effect of rotation on the learning of taste aversions. Bulletin of the Psychonomic Society, 1973, 1. 137-138.

lichtenstein, E., Harris, D. E., Birchler, G. R., WAHL, J. M., \& SChMAHL, D. P. Comparison of rapid smoking, warm, smoky air, and attention placebo in the modification of smoking behavior. Journal of Consulting and Clinical Psychology, 1973, 40, 92-98.

Marrone, R. L., Merksamer, M. A., \& Salzberg, P. M. A short duration group treatment of smoking behavior by stimulus saturation. Behavior Research and Therapy, 1970, 8, 347-352.

Singer, J. A. State and familiarity as determinants of selective attention in the four month old infant. (Doctoral dissertation, Boston University Graduate School, 1973) Ann Arbor: University Microfilms No. 73-14, 181.
Stang, D. J. Methodological factors in mere exposure research. Psychological Bulletin, 1974, 81, 1014-1025.

StANG, D. J. Effects of "mere exposure" on learning and affect. Journal of Personality and Social Psychology, 1975, 31, 7-12.

Wilcoxon, H. C., Dragoin, W. B., \& Kral, P. A. Illness-induced aversions in rat and quail: Relative salience of visual and gustatory cues. Science, 1971, 171, 826-828.

Zajonc, R. B. The attitudinal effects of mere exposure. Journal of Personality and Social Psychology Monograph Supplement, 1968, 9, 1-27.

(Received for publication May 2, 1975.) 